\title{
Educação dos profissionais de Saúde hoje - problemas, desafios, perspectivas e as propostas do Ministério da Saúde
}

\author{
No campo da Saúde, é indispensável que produção de \\ conhecimento, formação profissional e prestação de serviços sejam \\ tomados como elementos indissociáveis de uma nova prática.
}

\author{
Laura C. M. Feuerwerker*
}

* Doutora em Saúde Pública.

A o discutir a formação dos profissionais de Saúde e as novas diretrizes curriculares, é importante compreender as questões que estão em jogo. Ou seja, compreender qual a natureza das mudanças propostas, sua base conceitual e suas conseqüências para os que estão à frente das instituições universitárias.

Vivemos um momento histórico de tensão paradigmática. Essa tensão se revela em várias dimensões. Na ciência, questiona-se a organização dos campos científicos mediante grandes estruturas abstratas. Atualmente o reconhecimento da complexidade leva a ciência a produzir novas explicações, que rompem as fronteiras entre os diversos campos científicos e colocam em cheque a lógica da especialização e do conhecimento mediante a "desmontagem" dos objetos em suas partes, que imperam na operação definida pelo racionalismo. Nas ciências naturais, por exemplo, existe uma tendência crescente de buscar micropadrões de desordem e indeterminação, ao invés de construir explicações baseadas em modelos teóricos elegantes construídos sobre uma expectativa de ordem e determinação. Por essa razão, cada vez são mais tênues os limites entre disciplinas, entre as ciências sociais, biológicas e exatas e cresce de importância o desafio de a ciência ser capaz de dialogar com todas as formas de conhecimento, no sentido de ampliar sua capacidade de explicação.

As universidades também vivem um momento especial, em busca de ampliar sua relevância social. Atualmente a universidade não ocupa o mesmo lu- gar na produção do conhecimento, nem em sua difusão; além do mais, a produção de conhecimento e a formação profissional estão marcadas pela especialização, pela fragmentação e pelos interesses econômicos hegemônicos. Encontra-se assim limitada a potência das respostas produzidas pela universidade em relação a temas complexos e contemporâneos. Há, portanto, a necessidade de redefinir referenciais e relações com os distintos segmentos da sociedade no sentido de a universidade construir um novo lugar social, mais relevante e comprometido com a superação das desigualdades. No campo da Saúde, é indispensável que produção de conhecimento, formação profissional e prestação de serviços sejam tomados como elementos indissociáveis de uma nova prática.

No campo da Saúde, o momento histórico de tensão se revela pela incapacidade da maioria das sociedades de promover e proteger a saúde das pessoas na medida requerida pelas circunstâncias históricas. Tendo em vista a transição epidemiológica, o desafio da eqüidade e a necessidade de contenção de custos, há necessidade de reorientação da atenção, ampliando a promoção e articulando-a com as ações de cura e reabilitação, buscando a utilização mais racional da tecnologia e dos diferentes equipamentos de saúde. Tendo em vista a profunda insatisfação da população com a qualidade da atenção (o mais alto nível de satisfação em relação a um sistema de saúde é observado no Canadá e a taxa de satisfação é de apenas 50\%), é indispensável redefinir a relação entre os profissionais da Saúde e a população e 
redefinir os papéis na produção social da saúde.

$\mathrm{Na}$ área da Odontologia, além dessas questões, há outros desafios particulares a serem enfrentados para pensar e construir as mudanças na formação. Até há alguns anos, a prática privada predominava de maneira absoluta como alternativa de ocupação para os dentistas e sua inserção no sistema público estava limitada à atenção básica (gestantes e crianças) e à atenção ao trauma.

Mais recentemente, entretanto, começaram a se fazer sentir os limites do mercado privado e, diante da concorrência acirrada, as estratégias para conseguir vantagens dentro do mercado têm sido baseadas na especialização e na incorporação tecnológica.

Essas estratégias, no entanto acarretam aumento de custos, que levam, por sua vez a uma progressiva institucionalização das práticas profissionais, em decorrência da existência de um segmento social ainda mais restrito que segue com capacidade de compra privada dos serviços.

Também na Odontologia, ou até mais drasticamente, a transição epidemiológica impõe necessidade de revisão dos conteúdos e da orientação da formação, até então dirigidos, sobretudo, para o tratamento da cárie e suas complicações.

Deve-se destacar que as mudanças necessárias para superar a tensão existente, para enfrentar os problemas até aqui mencionados, são necessariamente profundas, correspondem a mudanças paradigmáticas, a reviravoltas importantes na maneira como se pensam e organizam todas as coisas.

As propostas de mudança na formação dos profissionais de Saúde orientadas pelas novas diretrizes curriculares e apoiadas pelo Ministério da Saúde estão orientadas à superação de alguns desses problemas. Pretende-se com elas chegar a ter profissionais críticos, capazes de aprender a aprender, de trabalhar em equipe, de levar em conta a realidade social para prestar atenção humana e de qualidade. Pretende-se que a universidade esteja aberta às demandas sociais e seja capaz de produzir conhecimento relevante e útil para a construção do sistema de saúde. Pretende-se também transformar o modelo de atenção, fortalecendo promoção e prevenção, oferecendo atenção integral e fortalecendo a autonomia dos sujeitos na produção da saúde.

\section{AS COMPETÊNCIAS GERAIS PROPOSTAS PELAS DIRETRIZES CURRICULARES}

Considerando as transformações ocorridas no mundo do trabalho, foram definidas competências gerais, indispensáveis para o exercício profissional em praticamente todas as áreas, mas contextualizadas para a Saúde.

Os profissionais devem desenvolver competências no campo da tomada de decisões, que lhes permitam desenvolver trabalho visando o uso apropriado, eficácia e custo-efetividade da força de trabalho, de medicamentos, de equipamentos, de procedimentos e de práticas. Também devem possuir habilidades para avaliar, sistematizar e decidir a conduta mais apropriada.

Também no campo da comunicação, há competências a serem desenvolvidas, já que os profissionais de Saúde devem ser acessíveis e receptivos na interação com os pacientes e a comunidade; manter a confidencialidade das informações, além de habilidades para comunicação verbal, não verbal, escrita e leitura.

Também são consideradas indispensáveis competências no terreno da liderança, tais como trabalho em equipe multiprofissional, compromisso, responsabilidade, empatia, habilidades para tomada de decisões, comunicação e gerenciamento de forma efetiva e eficaz.

Devem também estar aptos a realizar o gerenciamento e administração da força de trabalho, dos recursos físicos e materiais e da informação, além de ser gestores, empregadores ou lideranças na equipe de saúde.

Considerando a velocidade da produção de conhecimentos novos, é indispensável que os profissionais sejam capazes de aprender continuamente e, para tanto, necessitam aprender a aprender, além de responsabilidade e compromisso com a educação e o treinamento/estágios dos futuros profissionais.

No campo da Atenção à Saúde, todos os profissionais de Saúde devem estar aptos a desenvolver ações de promoção, prevenção, proteção e reabilitação ao nível individual e coletivo; assegurar que sua prática seja realizada de forma integrada e contínua com as demais instâncias do sistema de saúde; realizar seus serviços dentro dos mais altos padrões de qualidade e dos princípios da bioética (ética da vida); ter em conta que a responsabilidade da atenção à saúde somente se encerra com a resolução do problema de saúde, tanto ao nível individual quanto coletivo.

\section{PRINCÍPIOS PARA O DESENVOLVIMENTO CURRICULAR}

Ainda segundo as diretrizes curriculares, os cursos da área da Saúde devem contemplar o sistema de 
saúde vigente no país, buscando formar profissionais capazes de desenvolver atenção integral à saúde num sistema regionalizado e hierarquizado de referência e contra-referência e o trabalho em equipe.

A educação profissional deve estar orientada aos problemas mais relevantes da sociedade, de modo que a seleção de conteúdos essenciais deve ser feita com base em critérios epidemiológicos e nas necessidades de saúde.

Considerando tudo o que há acumulado a respeito do processo de aprendizagem de adultos, é fundamental a utilização de metodologias ativas de ensino-aprendizagem, que possibilitam a construção dos conhecimentos a partir dos problemas da realidade, bem como a integração de conteúdos básicos e profissionalizantes, a integração entre teoria e prática, bem como produção de conhecimento integrada à docência e à atenção.

É indispensável a diversificação dos cenários de prática, que deve estar presente ao longo de todo a formação, de modo que os estudantes tenham a oportunidade de aprender e trabalhar em todos os espaços em que se dá a atenção à saúde.

\section{PREMISSAS FUNDAMENTAIS PARA A PROPOSTA DO MINISTÉRIO DA SAÚdE}

Partimos do pressuposto de que mudanças com essa orientação implicam a transformação de concepções e práticas e também de relações de poder; implicam a produção de novos conhecimentos e saberes. Elas têm que ser construídas com base na reflexão crítica sobre as práticas vigentes e em parceria, entre universidades, serviços de saúde e população, pois nenhum dos atores participantes tem todas as respostas e ferramentas necessárias à sua implementação. Os processos de mudança necessários serão complexos e as universidades necessitam de apoio técnico e político para realizá-los.

Considerando a importância estratégica que a mudança na universidade tem para a consolidação do sistema de saúde, o Ministério da Saúde apresenta um convite às universidades: romper com a lógica da "compra de produtos" e "pagamento por procedimento" que havia sido estabelecida nos últimos anos (quando o Ministério "encomendava e comprava” cursos, pesquisas etc.).

Propomos, como alternativa, negociar iniciativas inovadoras e articuladoras em quatro campos: produção do conhecimento, educação permanente, mudanças na graduação e prestação de serviços.

As universidades que se dispuserem a colaborar com o sistema de saúde nesses quatro campos rece- berão apoio técnico e financeiro para trabalharem suas mudanças. Dentre as estratégias de apoio estão o acompanhamento do desenvolvimento dos projetos, atividades de capacitação e de debate; a formação dos formadores e a oportunidade de conhecer e compartilhar os conhecimentos e as experiências acumuladas nas tentativas de mudança.

Além do trabalho no interior de cada escola e em articulação com o SUS, será fundamental e indispensável o trabalho articulado entre os Ministérios da Educação e da Saúde, pois são fundamentais políticas convergentes e coerentes para que as transformações possam atingir o núcleo duro da formação.

Será indispensável cooperação nos seguintes campos:

- incentivo à implementação das diretrizes curriculares;

- que a avaliação institucional seja utilizada como estratégia para fortalecer a mudança;

- que sejam alterados os critérios da avaliação docente, de modo a valorizar também a produção de conhecimento de interesse local, as práticas docentes e o trabalho em terreno;

- que se estabeleçam critérios para abertura de novos cursos superiores na área da Saúde, incluindo as novas profissões;

- que sejam estabelecidas políticas para especialização em serviço, transformando a residência médica e criando modalidades de especialização em serviço para as outras profissões da Saúde;

- ampliação e diversificação nos programas de pós-graduação lato sensu;

- políticas de financiamento de bolsas e de investigação em linhas de interesse do SUS;

- que haja políticas que propiciem a integração dos HUs ao SUS, bem como a inovação gerencial e nas práticas de atenção.

\section{ESTRATÉGIA NUCLEADORA}

Todas as instituições formadoras estão convidadas a integrar os Pólos de Educação Permanente em Saúde, que serão núcleos de articulação entre gestores municipais e estaduais do SUS, instituições formadoras e representantes do controle social.

Devem trabalhar com a proposta da educação permanente das equipes de saúde, possibilitando a articulação e o diálogo entre atores e saberes da clínica, da saúde coletiva e da gestão a partir das necessidades locais. Devem propiciar a superação de limites da formação e das práticas clínicas tradicionais: vínculo, responsabilização, integralidade da atenção, clínica ampliada, conhecimento sobre a realida- 
de, trabalho em equipe multiprofissional, intersetorialidade. Devem também ser o espaço para articulação e gestão da inserção de docentes e estudantes nos cenários de prática dos serviços de saúde dentro da mesma lógica de cooperação para atenção integral e de qualidade.
Esperamos contar com a participação cada vez maior das escolas de Odontologia nesse processo e ampliar efetivamente a inserção dos profissionais da área no sistema de saúde.

Aceito para publicação em 11/2003

\section{MUDANÇA \\ NAS NORMAS \\ PARA PUBLICAÇÃO}

A Revista da ABENO

alterou a normatização

das referências

bibliográficas para

o estilo Vancouver.

Veja as instruções na

página 94 antes de enviar seu artigo.

Colabore com nossa publicação! Envie seu artigo • - . . _ . 